Covered in: ERIH PLUS, CEEOL, Index Copernicus, CrossRef, CrossCheck, J-Gate, Google Scholar, Ideas RePeC, Econpapers, Socionet, KVK, WorldCat.

2018, Volume 6, Issue 2, pages: 57-62 | doi: https://doi.org/10.18662/lumenphs/11

\section{Selfie-fying the Landscape. Space Awareness through Social Media}

\author{
Cristina ENACHE1, Iulia \\ FLOROIU ${ }^{2}$
}

${ }^{1} \mathrm{PhD}$., Associate Professor, University of Architecture and Urbanism Ion Mincu, Faculty of Urban Planning, Department of Urban Design and Landscape Planning, Bucharest, Romania, cristina.enache@uauim.ro

${ }^{2}$ Teaching assistant, University of Architecture and Urbanism Ion Mincu, Faculty of Urban Planning, Department of Urban Design and Landscape Planning, Bucharest, Romania, arhitect.iulia@gmail.com

\begin{abstract}
Ever since William Whyte's The social life of small urban spaces (1980) we have become preoccupied with analyzing, understanding and predicting how users are going to react, behave or interact with their surroundings. We've noticed patterns, we've come up with formulas, we've written about space consumption, about design and public space becoming goods or products.

What experience and sensible research have shown is that in fact we are able to impact our environment just as much as it impacts us. Once you add social media to the mix you get the new urban citizen: the prosumer. He interacts with the city and his peers in a new way; within a slightly virtual, slightly surreal environment, he adapts design to his needs, he has the freedom to express himself with little regard to the (initial) intent of his surroundings.

He is the Millennial.

The undeniable force that is the power of the Millennials to see things differently, to experiment tirelessly, to brake rules without thinking about it has in fact changed the urban perception and social guidelines. Thus we observe a new trend, one that has developed organically throughout the last decade: the Space SELFIEfication.

The concept derives from the already well-established habitude of the space consumer, to take self-pictures with the surrounding landscape - natural or built landmarks. The study is an open-paper, continuing the preoccupation expressed in a previous research regarding the Landscape Consumerism and Social Sustainability, aiming to improve the relation between society and its surrounding landscape.
\end{abstract}

Keywords: Selfie-fying; landscape; prosumer; social media.

How to cite: Enache, C., \& Floroiu, I. (2018). Selfie-fying the Landscape. Space Awareness through Social Media. Logos Universality Mentality Education Novelty: Philosophy \& Humanistic Sciences, 6(2), 57-62. https://doi.org/10.18662/lumenphs/11 


\section{The Urban Landscape and Social Media}

The discussion about the Urban Landscape of the $21^{\text {st }}$ century becomes more and more related to the spaces of social interaction. The social media represents now the most important "place" of communicating, living, time spending, even relaxing or debating, promoting, electing, educating, making friends.

The landscape is that background of photos which supports the tags or posts and has that something that worth to be mentioned on Facebook, Instagram, Twitter or Linkedin. It's about image, about uniqueness, about symbol. The urban landscape offers contexts, situations, landmarks to be mentioned on internet posts.

Different studies about the relation between the urban space and social media reveals heritage concerns in the context of daily-life practices and everyday landscape (Ginzarly, Roders, \& Teller, 2018). Thus, the interactivity of landscape and other visual media appears to be intensifying (Despard, 2015).

\subsection{The social life in the Information and Communication Era - between reality and virtuality}

We are experiencing a duality - and this is no longer a novelty. Since the beginning of television the social life started to change, and that process became more complex with the internet phenomena explosion. Our life is a permanent switch between screens - the mobile phone, the computer, the TV, the real life.

The shift from traditional mass media to a system of horizontal communication networks organized around the Internet and wireless communication has introduced a multiplicity of communication patterns at the source of a fundamental cultural transformation, as virtuality becomes an essential dimension of our reality (Castells, 2010).

In the context of information and communication era, focusing on itself became more important while collective identity is lost and the individualization is growing. The internet offers to the individual an another activity field, which is in the same time personal and general. The virtual environment provide an apparent intimacy, but also an opening to the cyberspace. Thus, the entire existence of the contemporary society takes place between real and virtual, between physical space and informational space. This duality is not a competition, is the structure of our life, a life inbetween, in which the experience related to physical spaces becomes "real" when it becomes an internet post. 
The landscape has been gradually losing its transformative and multidimensional role in becoming a commodity. Instagram, Facebook, Twitter are the go to places to prove oneself, to live, to connect, all the while floating randomly within a space lacking both dimension and identity (Floroiu \& Enache, 2018).

This is the context of Millenials - generations grown-up with cell/smart-phones, personal computers / tablets, video-games/apps. Their personalities are marked and strong influenced by an increased use and familiarity with communications, media, and digital technologies. They are the users and the creators of the real and virtual space, the information society leaded by the technology being continuously developed by them. Their living environment is more than the city with its streets, buildings and parks, is an infinite space where the limit does not exists and where everything is possible.

So is it possible to stay within real space? And why would you?

\subsection{Landscape and Society}

From ancient times, the relationship between the society and its surrounding landscape was very intimate. The natural landscape represented the shelter, the resource, the inspiration, the potential, but also the unknown space, a space of threats and permanent lessons. The civilized society started to modify and to adapt the landscape to its own needs and comfort, and even creating new landscapes.

The urban landscape is an answer to society's effort to create an environment responsive to its demanding, comfort and trends. It is the reflexion of the society, the result of the natural - human interaction.

The landscape morphology and evolution are the spatial translation of the relationship between the society and the place. The link between a community and the landscape can be identified in the people's behaviour and the specific activities of the population, in the use of local resources and in the architectural style. Different societies gave birth to specific landscapes - syntheses of historical and cultural backgrounds.

The urban landscape of the 21 st century is an accumulation of different spaces, architecture, styles and landmarks, is the space where the informational society lives in. It is a mosaic, a puzzle of histories and places, with inhabitants belonging to another era. We are no longer related to the place, like our predecessors. Our landscapes need to be powerful, meaningful, unique, in order to provide that necessary environment to be appropriated, consummed, posted online and thus coming into existence in the other space - the internet. 


\subsection{Perceiving, understanding and appropriating the urban landscape}

Kevin Lynch, Christian Norberg - Schulz and Jan Gehl spoke about the perception and the understanding of urban space. About the quality of both the natural and anthropogenic landscape to be readable. About character and specificity, about symbols and landmarks. About meaningful spaces and the way the society perceives them.

The space needs elements to define it and organize it, in order to be identified by our consciousness. As Lynch said, the cities must be readable, so their inhabitants could understand them, appropriate them. The urban landscape needs a powerful image - as a result of the immediate perception and of the space memory. According to Norberg-Schulz (1985), man's being-in the-world is structured, and the structure is kept and visualized by means of architecture.

Nowadays, as Castells says, the space of flows has taken over the logic of the space of places, ushering in a global spatial architecture of interconnected mega-cities, while people continue to find meaning in places and to create their own networks in the space of flows (Castells, 2010).

\section{Selfie-fying the Landscape}

In the technological evolution context, the society's answer to the accelerated development (which no longer permits adapting and assuming the changes) focuses on doubling its existence in the virtual environment, which offers the advantage of indirect contact, of other choices, of semivirtual friendships, of computer / phone mediated interaction.

\subsection{About Selfie-fying. Defining a new concept}

Every time we open a social media application, we see it. One or more selfie-s, inside or outside, "feeling amazing", "feeling sad", "feeling motivated", me and my Facebook space. We are living in a virtual world of Selfie-s pics and its surroundings. We tag ourselves in interesting places that we are visiting, showing our presence in a selfie on Insta.

The speed of evolution of informational technology has far exceeded the rhythm and the adaptive capacity of the society. We used to talk about changes that occur in decades, but each of the last 20 years has brought innovations and progress unimaginable not long ago.

The way that people assimilate the changes is often unexpected and unpredictable. Domains like education, philosophy, culture become slowly inappropriate to a world in a continuous mutation. This is the general context in which we have to find ourselves beyond the traditional way to 
communicate, to educate, to promote. We have to be able to speak the same language in both environments. We have to be able to switch in a second the real world with the virtual one, from offline to online. It's not a sincere relationship, because - internet is not real life. At least, not now or not yet. But it is real enough to transform the way we think and connect.

Therefore - in this labyrinth of spaces / non spaces, where are our landmarks? how can we identify ourselves in relation to the space? Firstly, we have to see it. The space is the background of our lives. All we have to do is make it part of our double existence.

Selfie-fying is the action of establishing a link with the real space. With our surrounding landscape. Is that action which brings together spaces, people, existences. Is the way in which the individual can find its place in an uncertain world. A way of recovering an old relationship, lost in too much information.

\subsection{The Space Selfie-fication. Using a trend in order to promote the urban and natural heritage}

One of the possible ways to introduce the landscape into everyday life is learning the language specific to the period in which we live. Therefore, the space selfie-fication concept - through its belonging to both real / virtual world wants to define a strategy of education, promoting, revitalise the built and natural heritage by

- turning a trend of superficial interaction into an opportunity

- discovering potential - urban landscapes, industrial landscapes, natural landscapes, wetlands

- attracting people to connect, get involved, participate in the rehabilitation of the landscape

The Selfie-fication becomes a natural consequence of our need of adapting the education methods and the revitalizing strategies in order to value the cultural heritage and the natural environment, in a vision of sustainability, awareness and preservation, but also of assuming the now and future living environment.

\section{Outlining possible research directions}

Being an open-paper, this research wants to find directions to be explored, searching for new ways to adapt to the accelerated technology changes. There are a lot of mutation on the society level, mutation determined by the increasingly difficult assimilation of the IT development. 
As we know, a disfunction can be transformed in a potential. Thus, the issues arised through the social media evolution and conquest of the world, should become instruments in different activities, like education concerning heritage, natural environment, social crises, etc. Thus, a trend could be more than a superficial act of expression, could be a link between society and awareness.

A future research will analyse also possible risks, trying to outline the main domains affected or influenced by the tendency to strengthen the relationship between the real world and virtual world.

\section{Conclusions}

The study proposes a friendly approach of issues arising from the society's difficulty to keep up with an increasingly accelerating rhythm in which the man becomes from leader a compliant. A society where the faceto-face communication has no longer the same impact as 15 years ago, and where the new generations transmit the information easily through a screen than directly.

The Selfie is a trend in the Millenials world, and the main mistake that we use to do is to not taking seriously their trends, despising the superficiality. Their trends could be their future, also a smart and sustainable society would use them to build a new field of communication and education.

\section{References}

Castells, M. (2010). The information age. Economy, society, culture (2nd ed.) (vol. 1), The rise of the network society. Malden, USA: Wiley-Blackwell.

Despard, E. (2015) Photographic social media, designed landscapes and urban, place-based visibilities: in search of friction. Journal of Aesthetics and Culture, 7(1), e28242. doi:10.3402/jac.v7.28242

Floroiu, I., \& Enache, C. (2018). Landscape consumerism vs social sustainability. Recovering social connection within the urban landscape. EURAU 2018 Retroactive Research International Conference Proceedings. Retrieved from https://congresos2017.ua.es/eurau/eurau-2018/paper/viewFile/660/132

Ginzarly, M., Roders, A. P, \& Tellera, J. (2018) Mapping historic urban landscape values through social media. Journal of Cultural Heritage. doi:10.1016/j.culher.2018.10.002

Norberg-Schulz, C. (1985). The concept of dwelling: On the way to figurative architecture. New York, USA: Rizzoli. 